\title{
A Survey Report on Structural Factors Influencing English Majors' Agency in a Chinese University
}

\author{
Qiuming $\operatorname{Lin}^{1}$ \\ ${ }^{1}$ Faculty of English Language and Culture, Guangdong University of Foreign Studies, Guangzhou, China \\ Correspondence: Qiuming Lin, Faculty of English Language and Culture, Guangdong University of Foreign Studies, \\ No.2, Baiyundadaobei, Guangzhou, 510421, China. Tel: 86-137-9811-7687. E-mail: linqiuming@gdufs.edu.cn
}

Received: August 8, 2015 Accepted: August 20, 2015 Online Published: October 12, 2015

doi:10.5430/ijelt.v3n1p20 URL: http://dx.doi.org/10.5430/ijelt.v3n1p20

\begin{abstract}
Learner agency has increasingly come to be regarded as a necessary construct in understanding language learning. It is not a fixed entity that learners possess, but a contextualized and culturally-specific construction, mediated by socio-cultural structures. This paper reports a survey addressing the structural factors influencing English majors' agency by conducting a series of interviews with different groups of informants in a university in mainland China. Based on a theoretical framework that has been built on previous theories, the survey has explored factors from two aspects - schemas and resources, and at three levels - context, setting and self. The survey also finds that the same structural factors can be constraining or supportive for different learners, and suggests that as learner agency is mediated largely by exterior contextual conditions, students are not wholly to blame for the low agency that they have manifested in their learning process.
\end{abstract}

Keywords: learner agency, structural factors, Chinese learners of English, EFL learning

\section{Introduction}

Learner agency has increasingly come to be regarded as a necessary construct in understanding language learning (Lantolf \& Thorne, 2006; van Lier, 2008). Agency has been defined as the socio-culturally mediated capacity to act (Ahearn, 2001), and vanLier (2008) notes that language learners' agentive capacity to act runs contrary to any notion of linguistic competence as something one can possess; agency is instead "action potential, mediated by social, interactional, cultural, institutional and other contextual factors" (p. 171). Much of the post structurally informed research on identity has viewed learners as able to exercise their agency in making identity choices and in positioning themselves within and in response to local and larger social constraints (McKay \& Wong, 1996; Norton, 2000).

A recent micro-level discourse analyses (Lin, 2015) has further shown that agency is not a fixed entity that a speaker possesses, but constructed and negotiated dynamically by the speaker through narrative discourse. The following is an excerpt from the narrative about English learning in a life-story interview with one of the participants in Lin's study. The narrator Vivian, a female sophomore at the time of the interview, is an English major in the Faculty of English Language and Culture (FELC) in Guangwai (GW), a prestigious university in southern China. The style of the original Chinese has been maintained to the utmost in the English translation.

I took part in the drama contest on June 6. The drama contest, as we know, is a traditional event in FELC. I think, as I am a student in FELC, I should ... I myself like participating in these activities. Therefore I entered my name for it. /During this contest, although I was just an actress, and I participated in it as a minor role, but each, each rehearsal, I had to attend. Originally, what I interviewed for is a leading role, but after all it's a contest for third-year students, so the leading actors or actresses are generally the juniors. Then the director finally assigned me to a minor role. At that time I also have other engagements, so I thought as I was unable to play a leading role, playing a minor role had not much bearing in fact, as long as it wouldn't take up too much of my time, since I was quite busy at that time. However, after I really got in, I felt that it did take up much time. This is not the point. The point is I have gained a lot. The core members of the crew have influenced me deeply, especially the director. She is an enterprising person. The script is, the adapters adapted (the script) from the 
classical Shakespeare's play. I read through the script. I really envy them. I really admire them. They can take English as a tool of their own. I think they are awesome. I felt content if I can reach their level. After I got in, a great change in me is, as I view it, English leaning is not a burden. If I can master English, and take it as a tool that I can use skillfully, as far as I am concerned, this is happiness. I like English better and better.

Lin (2015)'s detailed textual analyses has demonstrated that even in a short narrative discourse like the excerpt, speakers navigate the agency dilemma by moving back and forth between a low-agency level and a high-agency level. Agency fluctuates quite violently from the beginning to the middle part when Vivian talked about why she took part in the drama contest, why she played a minor role, and how she consoled herself into accepting the minor role. Then agency keeps a relatively low level when Vivian talked about how she felt after becoming a member of the cast. After that, agency turns up towards the end when Vivian expressed her desires for English learning.

Based on the results of the discourse analyses, Lin suggests that agency is an identity dilemma, in which the individual constantly constructed and negotiated a relationship with the world. It is a contextualized and culturally-specific construction, mediated by socio-cultural structures. Chinese learners of English navigate their agency dilemma under socio-cultural structures in Chinese context, and it is the socio-cultural structures in Chinese context that we are particularly concerned with in this survey. The objective of the survey is to explore the structural factors influencing agency construction and navigation by students majoring English in Chinese universities.

\section{Literature Review}

There has been a wealth of studies on agency of Chinese learners of English. Most of these studies are done by domestic teachers and educators. A great majority of the research is focused on the strategies to boost students' agency (e.g. Wang \& Wang, 2008). A few studies explored the factors (e.g. Zhou, Jiang \& Hong, 2012) and manifestation of student's agency (e.g. Su, 2013).

However, studies on agency of Chinese learners of English so far focus only on learning agency in classroom, and Chinese researchers have only examined the factors affecting classroom agency, especially the local factors from teachers and settings. They have found that teachers play a decisive role in activating students' agency in classroom by means of teaching content (e.g. Zhang, 2000), teaching methods and techniques (e.g. He, 2008; Liu, 2013; Wei, Wang \& Yan, 2014), ways of commenting and evaluating (e.g. Fan, 2012). Under the guidance and supervision of teachers, students' ways of learning is also important. "Explorative learning" is suggested to be the most effective for promoting learning agency (Zhao, 2014). Multi-media settings and advanced teaching facilities in the classroom may be helpful for students to acquire knowledge and develop skills, but they may also be constraining factors and students may become passive and fail to achieve the learning objectives (Tong, 2014).

Zhou, Jiang \& Hong (2012) have tried to observe non-classroom factors on agency of Chinese university students in general. Based on relevant literature and their empirical experience, the researchers chose three factors and investigate how these factors work on students' agency. The three factors include personal features, family background and academic performance. Through large-scale questionnaires, they have found that 1) male students tend to have lower agency; 2) freshmen tend to have lower agency; 3) students who are confident about future tend to have higher agency; 4) students from families with ordinary economic conditions tend to have lowest agency; 5) students receiving more awards tend to have higher agency. We suspect that these conclusions may not be universal across disciplines, and other factors may be even more influential for English majors' agency.

Given the current literature about English learners' agency in China, we can see that empowerments and constraints on learning agency from larger social context in China seem to have been ignored by Chinese researchers. In order to explore these structural factors comprehensively, we propose the following theoretical framework as the foundation of our survey.

\section{Theoretical Framework}

This survey is based on a theoretical framework integrating Sewell's theory of structure (1992) and Gao (2013)'s explication of interaction between language learners and contextual/structural conditions. We now look at these two theories briefly and then build our own framework on the basis of the two.

\subsection{Sewell's Theory}

In his theorization of the dialectic relation between"agency" and "structure", Sewell (1992) has defined the concepts as follows. 
Structures are "sets of mutually sustaining schemas and resources that empower and constrain social action and that tend to be reproduced by social action" (p.19). According to this definition, structures have two components: schemas and resources. Schemas are cultural in the sense that they are "generalizable procedures applied in the enactment/reproduction of social life" (Giddens, 1984:21). They have a "virtual" existence in the sense that they are "capable of being actualized or put into practice in a range of different circumstances" (Sewell, 1992:8). Resources are "anything that can serve as a source of power in social interactions" (p.9). Resources are of two types, human and nonhuman. They have an "actual" or material existence.

Structures are dual and dynamic because they have a bidirectional relation with social actions. On the one hand, the current structures have impacts on social actions by either empowering or constraining them. On the other hand, they can also be reproduced by social actions. All this is done through the agency of agents. "To be an agent means to be capable of exerting some degree of control over the social relations in which one is enmeshed, which in turn implies the ability to transform those social relations to some degree" (p.20). This capability of the agent is agency. "Agency arises from the actor's knowledge of schemas, which means the ability to apply them to new contexts....agency arises from the actor's control of resources, which means the capacity to reinterpret or mobilize an array of resources in terms of schemas" (p.20). In other words, agency is the capacity to transpose and extend schemas to new contexts, and to have access to resources of one kind or another. This definition indicates that the virtual schemas and actual resources making up structures are two sources of agency. The schemas enable agents to mobilize resources which are available to them, and the resources enable agents to enact schemas in their mind. When the agents have knowledge of schema as well as the control of resources, they have agency to act.

Agency differs in its kinds and degrees. The nature of particular structure determines what kinds of agency the agents can have, and the social positions of the agents determine the extent of agency they can have. Sewell's theory of structure can be illustrated by Figure 1 .

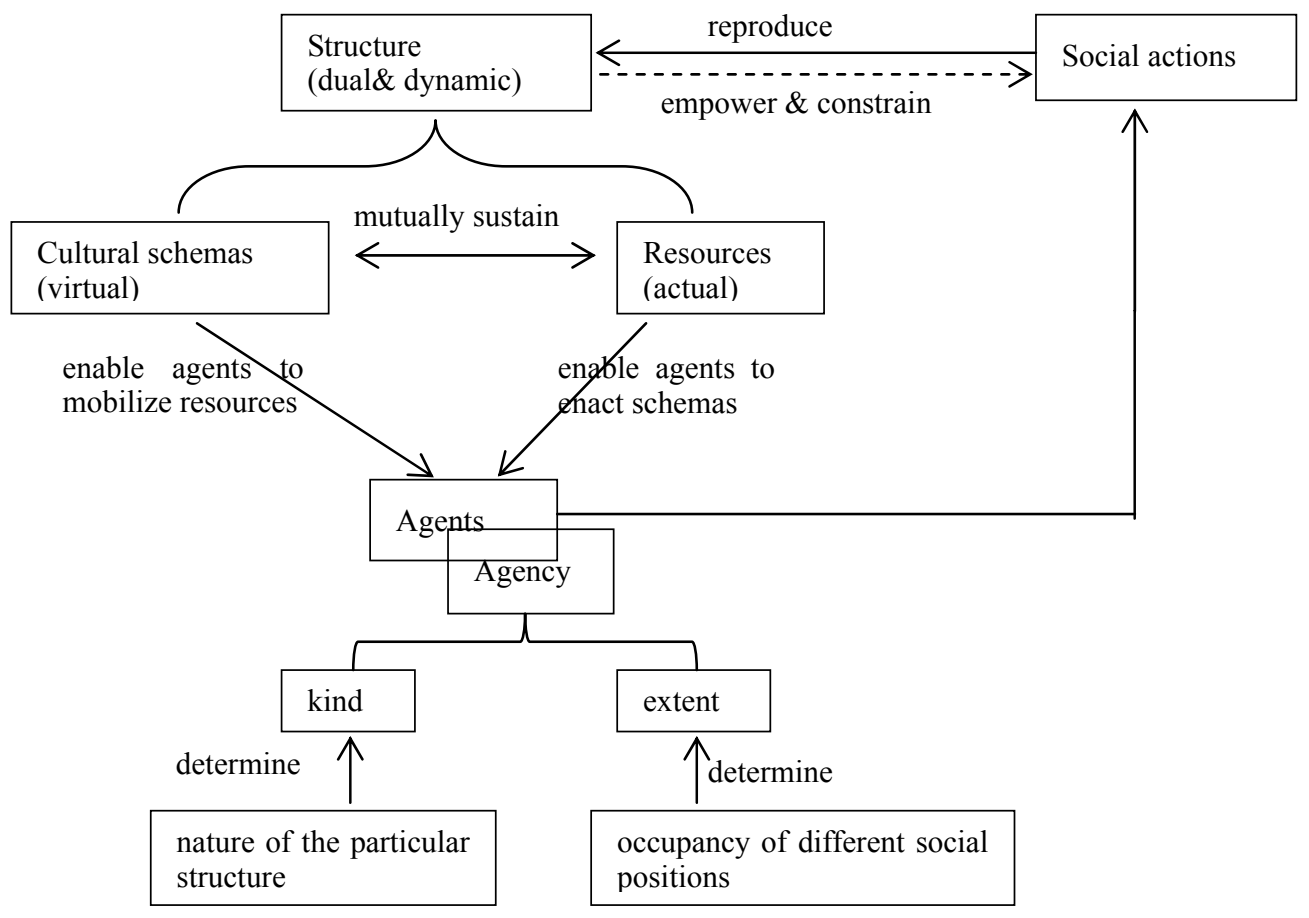

Figure 1. Agency and structure (Sewell, 1992)

\subsection{Gao's Theory}

Drawing on Ahearn's (2001:122) definition of agency as 'the socio-culturally mediated capacity to act", Gao (2013) theorizes language learners' agency as a precondition to their efforts to take control of the learning process and proposes reflexive/reflective thinking as a means to examine how agency enables learners to exercise their autonomy. 
His central argument is that language learners' exercise of autonomy, or their capacity to take control of one's own learning, depends on their agency through reflexive/reflective thinking or thinking during action and postevent in the learning process.

According to Gao, autonomy in language learning may be considered as a particular type of power resting in language learners and proper to learner agency, which allows them not only to take control of language learning but also 'open access to learning opportunities' and 'seek culturally alternative paths to learning' by changing contextual/structural conditions (Gao, 2007b; Oxford, 2003). Such interaction between learners and contextual/structural conditions underpinning autonomous language learning can be summarized as in Figure 2 .

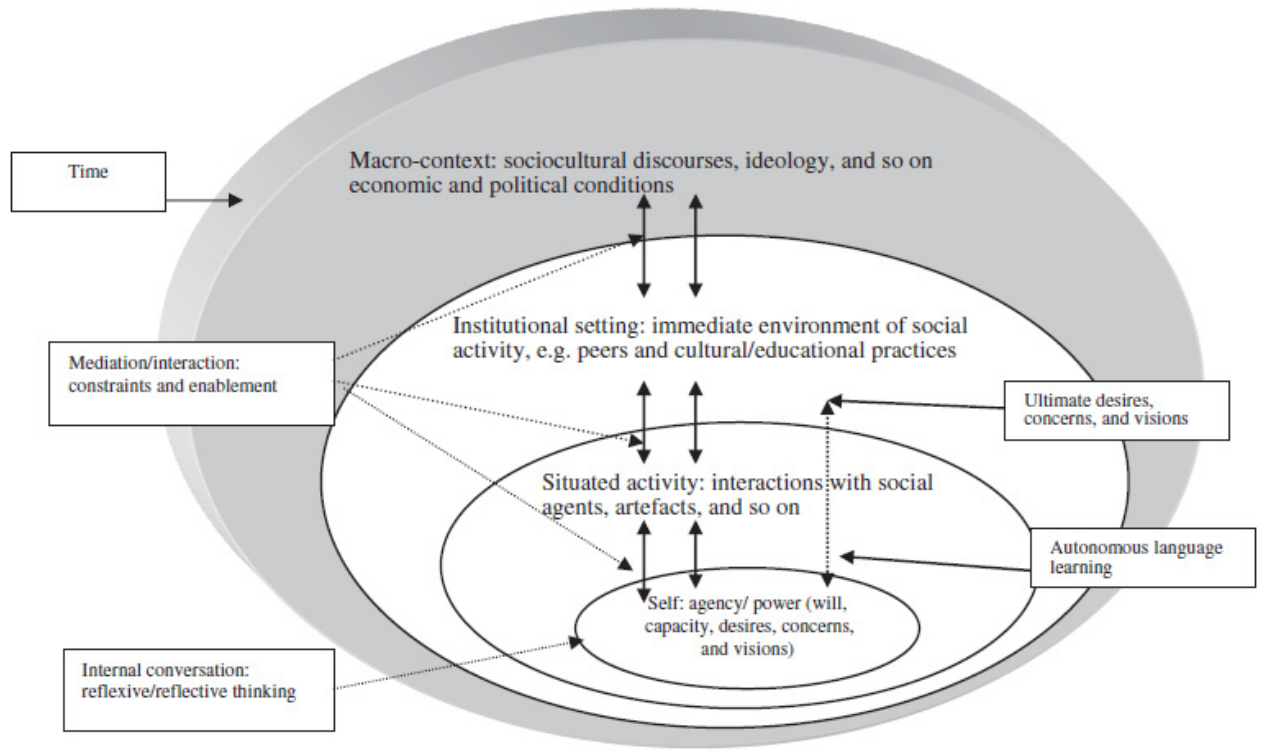

Figure 2. Interaction between language learners and contextual/structural conditions (Gao, 2013)

The figure has four components: context, setting, situated activity, and self. Context (macro-context) refers to societal discourses about language learning, the economic situation, intergroup social relationships (e.g., social classes), and political conditions. Setting is the immediate environment for language learning. The setting contains contextual resources, including material, discursive, and social resources (Palfreyman, 2006), that language learners can potentially access. In specific terms, they may refer to physical learning settings, cultural artifacts (e.g., English-medium universities), material conditions, and so on. The setting also encompasses social relationships between the learners and the mediating agents such as teachers, peers, and friends. Situated activity (i.e., autonomous language learning) refers to the interaction between the learners and the contextual resources, including mediating agents (social resources) in particular settings. Self is the learners' self-conceptualization and biographical experiences. Self is also where learner agency and power are located, which includes the learners' will (e.g., concerns, desires, and visions) and capacity to act in and control the learning process. A crucial element in this framework is the historical dimension (referred to as time in the figure) as four different components of the framework consistently interact with each other, leading to the emergence of temporal, contextual reorganization, and changes in the learners (i.e., their will and capacities to act). As a result, the exercise of autonomy is always emergent and relative to individual learners in particular contexts because the nature of such capacity is developmental and its exercise is subject to ongoing contextual mediation (Benson, 2007; Gao, 2007a; Sealey \& Carter, 2004)

It must be noted in this framework that language learners can modify the contextual/structural conditions, transforming these conditions into either supportive or constraining ones for the pursuit of learning, although they are placed in priori contextual/structural conditions and through an ongoing interaction between the learners and contextual/structural conditions.

\subsection{Theoretical Framework of the Survey}

Sewell's theory (1992) emphasizes the duality of structure - structures affects and is affected by human agency, but 
the concept of "structure" is abstract in the theory. It only tells us that structure consists of a visual part "schemas" and a material part "resources", but what exactly are the schemas and resources is not specified. Gao's theory (2013) is more substantial in that it specifies three levels of structures: context, setting and situated activity, each with clear explanations and examples. These structural conditions have interactions with "self", where agency rests in. However, he didn't make a distinction between visual and actual structures. Sewell's distinction of schemas/resources and Gao's segmentation of context/setting/activity are two perspectives to dissect "structure". We propose a more comprehensive framework for our survey (see Figure 3) by integrating the two perspectives.

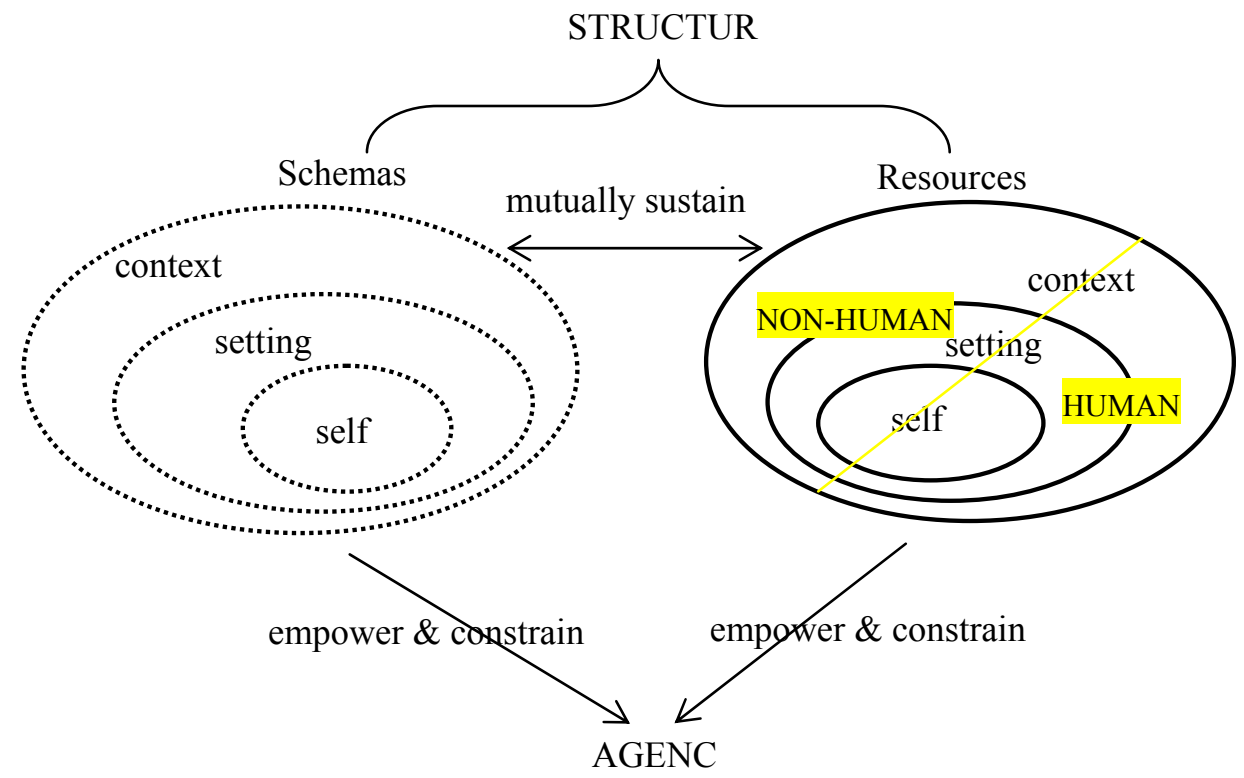

Figure 3. Structural factors on agency

Following Sewell (1992), structure consists of schemas and resources in this framework. Schemas are presented by dotted lines as they are virtual and cultural, while resources are presented by solid lines as they are material and actual. Some resources are human; others are non-human. Schemas and resources are mutually sustaining, because schemas can be actualized by resources and resources can be transformed to schemas. Both schemas and resources, as structural conditions, have three components: "context", "setting" and "self". We combine the component of "situated activity" in Gao's theory (2013) into "setting", as we consider the learning activity itself is also a kind of setting for agency construction. Moreover, Gao contrasts structural conditions to the learner, but in our framework, "self" is a part of "structure", because it also contains both schemas and resources that enable or constraint agency. In ideological and material ways respectively, schemas and resources have positive or negative impacts on learner's agency. In figure 3 we only indicate the unidirectional effect of structure on agency, but that doesn't mean that agency do not have impacts on structures. It is only because our survey only investigates the structural factors on agency that the transforming effect of agency on structures is not the issue we are dealing with here.

Given the established framework, the general objective of the survey stated in the introduction section can now be specified into three research questions:

Q1: What macro-contextual factors influence learning agency of English majors in Chinese universities?

Q2: What local setting factors influence learning agency of English majors in Chinese universities?

Q3: What individual factors of the English majors in Chinese universities influence their learning agency?

All the three research questions will be explored from the two components of structure respectively - visual schemas and material resources. 


\section{Method}

This survey is a qualitative inquiry. It starts from case studies with the English-learning story-tellers, and then extends to inquiries with different groups of informants. The data of the survey come from a series of interviews as shown in Figure 4.

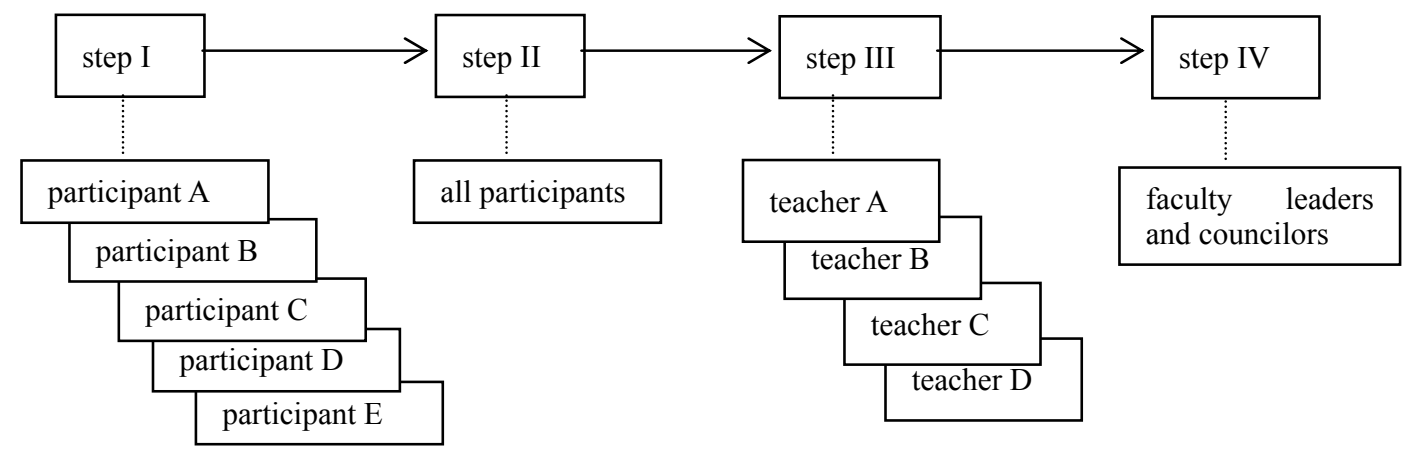

Figure 4. Interviews in the survey

Interviews at step I are individually conducted with the participants, three female and two male, all English majors in FELC for 1-4 years. Each interview consists of two parts. The purpose of the first part is to elicit English learning stories from the participants. Barkhuizen (2013) suggests that narratives of language learning experience reflect the dynamic sociocultural features embedded in the process of language acquisition. Learners' narratives have embodied the learning action and identity construction, so that they can reveal the relation between learners' agency and learners' identity. The second part of the interview is to retrieve the reasons from the narrators themselves for agency construction and navigation in their narratives. For example, for the utterance of "I should ... I myself like participating in these activities" in the excerpt given in the introduction section, we asked Vivian "why did you say you 'should' participate? From where comes the obligation? Why did you say you 'like' joining these activities? What gives you the pleasure?"

Interview at step II is a focus group with all the participants. The questions we asked in this interview include "What do you think about your English learning now? Are you active in it? What gives impetus to your learning? What makes you lose enthusiasm in learning English?" etc.

Interviews at step III are individually conducted with four teachers in the faculty, two male and two female. They have 2, 5, 10 and 25 years' experience of teaching English majors respectively. The central question we asked them is "what do you think will affect students' agency in learning English in the class as well as after the class?"

Interview at step IV is another focus group with two faculty leaders (the secretary and vice-secretary) and four councilors who are responsible for monitoring students' campus activities. These people are administrative staff in the faculty, and familiar with the relevant national and institutional regulations. Therefore the central question we asked in the interview is "what social factors from the faculty, the university, the government, the family, etc. do you think will affect students' agency in English learning?”

All the interviews have been recorded and later transcribed. The transcribed data is then analyzed in three steps. First, the data is read for a general idea of the various issues involved. In this step, we retain the issues that are related to the objective of the survey and remove those that are considered as irrelevant and repetitive. In the second step, we code and categorize the transcribed data in terms of their main themes. Finally, we refine the categories and establish connections between them for discussions below.

\section{Results and Discussion}

Based on our theoretical framework, we report our findings of the structural factors influencing English majors' agency from two aspects - schemas and recourses. Each is represented at three levels: context, setting and self.

\subsection{Schemas}

5.1.1 Context: The Status and Use of English in Mainland China

After careful analyses of the interview data, we have found that the changing status and use of English in mainland 
China today constitute the schemas that have major impacts on English learners' agency at the macro context level. There are two dominating yet mutually competing socio-cultural discourses related to the status and use of English.

\section{A. English at a decreasing status in mainland China}

The state government seems to have diverted their attention from teaching and learning of foreign languages to that of the mother tongue in recent years. The total score of the English exam has been reduced and that of Chinese has been increased in the college entrance examination. That means the proportion of English in the college entrance exam has been reduced. It is not impossible in the future that the subject of English be simply cancelled in the college entrance exam. This preferential policy of the state gives messages that English is no more as important as it was in China, and it is inevitable that teachers and students in middle school will reduce their investment on English.

Moreover, English-related job opportunities are fewer now than ten years ago. English language and literature has been listed for successive years as one of the disciplines of which graduates have greatest difficulties to find jobs, according to Employment Report of Chinese Graduate by MyCOS Data, the leading higher education consulting firm in China. Seniors come back from the job fairs with the message to their juniors that very few working posts recruit English majors. Even if they recruit English majors, they also have other requirements, e.g. computer skills, communicative skills, organizing and managing abilities, or even relevant work experience. Possessing only English knowledge and skills can hardly meet the requirements of the jobs. Besides, many employers attach importance to the reputation and status of universities. "They only consider graduates from universities of the "985 program" or "211 program", said the faculty secretary, "and this is unfair for our graduates, who are no worse than the students from those universities." It is this market trends and orientation of social values that cause worries and anxieties to many English majors in GW, which is not listed in either of the programs. Most of the students think learning English alone in four years in university is not worthy, since commanding only English skills upon graduation is not competitive enough. The natural reaction is that they take up a second major: accounting, laws, trade, etc. They strive for all kinds of certificates. They join various social activities with the aims to develop other abilities and accumulate "work experience". All this leads to the decline of agency in learning English.

\section{B. English still as the most popular international language}

English, as the native language of two super powers of the world, is still the most popular language, especially among the youth. One of the young teachers said, "Our students, influenced by the foreign media, have admiration of western living style. They are emerged in the global pop culture, watching English movies and TV series, listening English pop songs, following the western fashion. They are fascinated by the pop culture and following the western living style". All this prompts the students to command the English language.

What's more, English is still the common language of IT field in the world. As one of participants said, "If you don't know English, you can hardly follow the latest technology. All the advanced technology is accompanied by English specification, and the working language in international conferences and online exchange platforms is English." Therefore, English is still the most popular international language, and this discourse keeps promoting English learners' agency.

\subsubsection{Setting: The University}

Under this complicated macro context, the learning setting seems to provide a favorable schema for English majors in GW. There is a traditional discourse in this university: a cradle for graduates with excellent English skills.

GW developed from an institute of foreign languages and has been a leader in the field of language teaching and learning nationwide. With a history of 50 years, it has become an important base to cultivate foreign language talents for South China, and it is renowned for its graduates with excellent language skills. English language and literature has been appraised as a national key discipline by the state, so GW has always been laying stress on English teaching and learning. FELC is the oldest faculty to bring up English majors in GW. It is a tradition for English majors in GW, especially in FELC to study hard compared with those in other universities and other faculties. Students in FELC have passed on a hard-working learning culture over years. This traditional discourse creates a favorable atmosphere for students in GW, especially in FELC to keep up their agency in English learning.

\subsubsection{Self}

Interviews have shown that schemas affecting English majors' agency at the "self" level include individual learning conception and culture. Learning conception and culture has been shaped over years in the learner's education history. Early from primary and secondary education, the learner has formed conceptions about "study", including why to study and how to study, under the influence of schooling and family education. These conceptions normally 
will continue into tertiary education. It is evident that students with clear learning objectives and good learning habits will have better control of their actions, while those with no purpose or good habits will be less active in their learning. Besides, self-concept is also an influential schema. How the learner think about his or her English competence and performance will become an enablement or constraint for the learning process.

\subsection{Resources}

\subsubsection{Context}

Resources have an actual or material existence. It can be human and non-human. Resources at the context level are mostly non-human. They include the material and financial investment to English learning and teaching by the state. The degree of the investment is naturally related to the degree of attention given to the discipline as mentioned in the section of schemas above. It is also related to the total investment to (higher) education by the state. The national English tests also serve resources at this level. TEM4 (Test for English Majors - band 4) and TEM8 (Test for English Majors - band 8) are two important proficiency tests for second- and fourth-year English majors nationwide. The certificate of TEM8 represents the highest level of English skills in mainland China, and it used to be a prerequisite for English majors to acquire the BA degree in GW. One of the councilors told us in the interview that many employers recruiting English majors today still require the TEM8 certificate along with the degree certificate. Therefore the certificates are still powerful driving force for English majors.

\subsubsection{Setting}

\section{A. Human}

Human beings are prone to being influenced by others. For English majors, these "significant others" include family members, teachers and peers. They can serve as a source of power or an obstruction in the process of English learning.

The influence of family members. Parents' conception about English learning and other abilities' development has a direct impact on English learner's agency, either positively or negatively. Parents have different expectations and requests for their children because of their conceptions. They may expect their children to be so skilled in English that they won't have any difficulties in communicating with foreigners, reading English books, watching English movies, understanding English news broadcast. They may expect their children to study or work abroad after graduation. They may expect their children to master not only English, but also other knowledge and skills. They may ask their children to take a second major, or even to transfer to other majors. "Very few parents want their children to learn only English nowadays", said one of the interviewed teachers. Family education also varies because of parents' conceptions. Vivian told us, her parents entered her name for all sorts of activities and contests since she was a child. They always encouraged her to assert herself and improve herself through these opportunities. It is because of this tradition of family education that Vivian has actively engaged herself in numerous activities and contests in university, including the English drama contest that she mentioned in her narrative. And this is also the reason why she said "I myself like participating in activities like this." In addition, family background has an indirect but important bearing on English learner's agency. This background refers to the economic conditions, social status, and personal connections of the family. A strong and a weak background are both possible to cause a learner to act passively in English learning. Under the former, the learner may feel lack of the need to study hard, since everything will be arranged properly. Knowing that they are going to work for the family business or in an arranged job position, some students may slacken off since they don't have the pressure from job hunting. Under the latter, students may think they will never be competitive no matter how hard to study, since good jobs now are only available for those whose family has social power or personal connections.

The influence of teachers. Teachers' guidance and encouragement has a strong effect on students' agency. Both the students and teachers in the interviews emphasized the important role of teachers' feedback on students' performance. Teachers found that students act more agentively when they give affirmation and praise to students' performance in the class. However, for the jobs that they have labored to complete, simple and general affirmation and praise is not encouraging at all. One of the students said that she lost enthusiasm in writing compositions because the teacher always only marked "good" without more specific comments on her paper. Another student said, the higher requirements the teachers have, the more agentive the students are. He would feel more and more willing to spend efforts on the assignment, when he spent more and more efforts on it. What's more, the reputation of the professors or supervisors may also have a push to student's learning agency.

The influence of peers. Top students are normally regarded as examples and competitors by other students in the class. One will be spurred on by the desire to excel in the group and by the fear of lagging behind. When doing pair 
work or teamwork, one's agency will be promoted if the partner(s) work hard and perform well. The attitudes and acts of peers in the class or out of the class create a favorable or non-favorable setting for English learning. Moreover, peers' experience is also influential. One of the participants told us, her cousin has recently been admitted to a postgraduate program in a well-known university in the US owing to her outstanding English proficiency. She felt greatly impelled by this and started to work harder on English. Another student told us a different story. He just learnt from the internet that a college graduate started a company and his company has achieved great success, but before that he was a "poor" student in college, doing badly at the major courses. Thus his student began to doubt: "do I really need to work hard on my major?"

\section{B. Non-human}

One of the non-human recourses at the setting level is the courses. Usually students have higher agency for the courses they choose voluntarily than for the compulsory courses being arranged for them. "But there are too many compulsory courses," said the eldest teacher. "Students do not have much free time for optional courses. Consequently, students' learning agency decreases." Actually, no matter how many optional courses they take, students have to go through a four-year period before they can graduate from the university with a bachelor's degree, as GW is currently running a 4-year set-course system rather than a credit system. Students are provided 3-5 compulsory courses every semester in the four years (except the last semester in which they don't have any causes but have to finish writing their dissertation). This means students have to follow the prescribed order of the compulsory courses and there's no way to shorten the length in university. And there's influence from non-English courses. Sometimes these courses may consume much time and energy of the learners and therefore affect their investment on English learning. Sometimes things are just opposite. One of the students said: "The course of Website Designing is very difficult. And there's no sense of achievement at all. After taking this course, I want to spend more of my time on English."

Other non-human recourses include English learning activities and facilities available. The more activities and the better facilities, the more favorable conditions and environment for English learning, the more encouraged and agentive the learners are. What's more, an effective evaluation system of students' academic performance is also helpful. If the test scores cannot differentiate the students' efforts, their agency will definitely decrease. Furthermore, opportunities of internship may bring double-edged effect. They may facilitate English learning process (if it's related to English) on one hand, and they may become one of the many distractions that hinder students' English learning today on the other.

\subsubsection{Self}

Resources at the "self" level are usually called the "learner factors" in second language acquisition. These factors include interest, capacity, motivation and concerns, which will affect how much learners will devote themselves into English learning, and in what ways they are going to learn English. Engagement with hobbies such as sports, music and arts will inevitably distract students' time and energy, which otherwise can be spent on English learning. On the contrary, English-related interest can boost students' agency in learning English. For example, as a teacher told us, one of her students like doing translation very much. She spent a lot of free time doing extra-curricular translation and frequently gave her work to the teacher for revision. Obviously the agency for doing this kind of exercises comes from her interest in translation.

Learners' capacity to control the learning process is also important. One of the participants told us, she felt like being kidnapped in her studies. Although she knew she must study English hard and she really wanted to spend more efforts, there were too many distractions in her life that prevented her from doing so. A student with capacity to steer learning process can maintain the balance between English learning and other activities and grasp the initiative all the time.

Motivation is another crucial resource. Motivation, be it instrumental or integrative, is the driving force for English learning. Many English majors want to work in the international companies with foreigners. Some plan to study abroad for higher degrees. Vivian wants to be a business woman. She desires to achieve success in everything and receive praise. She likes projecting herself by winning prizes of all sorts of contests, so she went for the dancing contest, the English drama contest, etc. We can see Vivian's desires motivate her English learning on one hand, and hinder it on the other.

Finally there are leaners' concerns. When Vivian was asked why she thought she "should" participate in the drama contest, she explained "because this is what I am supposed to do. If I don't, people will say 'hey, you are an English major. Why didn't you go for this?"' This kind of concern of other's expectations or opinions is another factor for 
Vivian to join in English-related activities.

The results of the survey are summarized in Table 1, addressing the three research questions respectively.

Table 1. Structural factors influencing the agency of English majors in mainland China

\begin{tabular}{lll}
\hline $\begin{array}{l}\text { Structural } \\
\text { Factors }\end{array}$ & Schemas & Resources \\
\hline Context & $\begin{array}{l}\text { English still as the most popular } \\
\text { international language; } \\
\text { English at a decreasing status in } \\
\text { mainland China }\end{array}$ & $\begin{array}{l}\text { non-human: governmental investment to English learning and } \\
\text { teaching; } \\
\text { national tests set for English majors }\end{array}$ \\
& $\begin{array}{l}\text { tradition and orientation of the } \\
\text { faculty and university }\end{array}$ & $\begin{array}{l}\text { human: influence from family members, teachers and peers; } \\
\text { non-human: courses, English learning activities and facilities, } \\
\text { evaluation system, opportunities of internship }\end{array}$ \\
\hline Self & $\begin{array}{l}\text { individual learning conception } \\
\text { and culture, self-concept }\end{array}$ & human: individual interest, capacity, motivation and concerns \\
\hline
\end{tabular}

\section{Conclusion}

In this survey report, we have sketched a general picture about the structural factors influencing English majors' agency in a university in mainland China, with the purpose of excavating the hiding forces for agency construction and navigation in English learning by English majors in mainland China. We have focused our discussion on learner agency outside classroom because the current literature has mostly addressed the factors affecting agency in classroom.

Through a series of individual and group interviews, we have explored factors that have impacts on English learners' agency at three levels in schemas and resources respectively. As Table 1 shows, at the context level, there are two dominating yet mutually competing socio-cultural discourses as influential schemas: English still as the most popular international language and English at a decreasing status in mainland China. The governmental investment to English learning and teaching and the national tests set for English majors constitute powerful resources. At the setting level, GW is famous for cultivating students with excellent English skills. This traditional discourse has provided a favorable schema for students in GW, especially in FELC to keep up their agency in English learning. Family members, teachers and peers are significant in their influence on the learner and constitute important human resources, while non-human recourses including English as well as non-English courses, English learning activities and facilities, evaluation system, opportunities of internship, etc. also play a role. At the learners' level, there are many crucial factors too, including individual learning conception and culture, self-concept as schemas, and individual interest, capacity, motivation and concerns as recourses. All these contextual and structural conditions can be constraining or supportive. Even the same condition may be a driving or a hindering force at different time and for different learners.

We believe that there must be still other structural factors that have been missed in our survey due to the limit of the data we have collected, and we have located our survey in just one university. In order to make the picture in China more complete, further surveys and investigations need to be done with more informants and in different research sites.

We hope that this survey, in spite of its limitations, can raise the awareness of Chinese researchers in English teaching and learning. As learner agency is mediated largely by exterior contextual conditions, students are not wholly to blame for the low agency that they have manifested in their learning process. Teachers are not the only people who will influence students' agency, and classroom is not the only site for students to exercise their agency, especially for college English majors. As EFL researchers, we also need to show solicitude for larger social background, which may produce more fundamental impacts on learners' agency, and hence influences learners' investment on the target language and strongly facilitates or hinders the language learning process. 


\section{References}

Ahearn, L. M. (2001). Language and agency. Annual Review of Anthropology, 30, 109-137. http://dx.doi.org/10.1146/annurev.anthro.30.1.109Benson 2007

Barkhuizen, G. (2013). Narrative Research in Applied Linguistics. Cambridge: Cambridge University Press.

Benson, P. (2007). Autonomy in language teaching and learning. Language Teaching, 40, 21-40. http://dx.doi.org/10.1017/S0261444806003958

Fan, H. (2012). Strategies to activate students' learning agency. Studies in Chinese, Mathematics and English, 09, 61

Gao, X. (2007a). Language learning experiences and learning strategy research: voices of a mainland Chinese student in Hong Kong. Innovations in Language Learning and Teaching, 1, 193-207. http://dx.doi.org/10.2167/illt011.0

Gao. X. (2007b). A tale of Blue Rain Café: A study on the online narrative construction about a community of English learners on the Chinese mainland. System, 35(2), 259-270

Gao, X. (2013). Reflexive and reflective thinking: a crucial link between agency and autonomy. Innovation in Language Learning and Teaching, 7(3), 226-237, http://dx.doi.org/10.1080/17501229.2013.836204

Giddens, A. (1984). The Constitution of Society: Outline of Theory of Structuration. Berkeley, CA: University of California Press.

He, Y. (2008). On developing students' agency in English learning in vocational schools. Journal of Chongqing University of Science and Technology (Social Science Edition), 07, 221-222.

Lantolf, J. P., \& Thorne, S. L. (2006). Sociocultural theory and the genesis of second language devel-opment. Oxford: Oxford University Press.

Lin, Q. (2015). An Ideational-Functional Analyses of Agency Construction and Navigation in Narratives of English Learning by Chinese Learners. Unpublished PhD dissertation.

Liu, Y. (2013). How to promote students' agency in English learning? Read and Write Periodical, 07, 111.

McKay, S. L., \& Wong, S. L. (1996). Multiple discourses, multiple identities: Investment and agency in second-language learning among Chinese adolescent immigrant students. Harvard Educational Review, 66(3), $577-609$.

Norton, B. (2000). Identity and language learning: Gender, ethnicity and educational change. Harlow, England: Pearson Education Limited.

Oxford, R. (2003). Towards a more systematic model of L2 learner autonomy. In Learner Autonomy across Cultures: Language Education Perspectives, edited by D. Palfreyman and R. C. Smith, 7592. Basingtoke: Palgrave MacMillan.

Palfreyman, D. (2006). Social context and resources for language learning. System, 34, 352-370. http://dx.doi.org/10.1016/j.system.2006.05.001

Sealey, A., \& Carter, B. (2004). Applied Linguistics as Social Science. London: Continuum.

Sewell, W. (1992). A theory of structure: duality, agency, and transformation. American Journal of Sociology, 98, $1-29$.

$\mathrm{Su}, \mathrm{Z}$. (2013). Different agency manifestations of teachers and students in college English teaching and learning. College Entrance Examination, 01, 10.

Tong. (2014). An experimental study on college students' dynamic role in English Visual-Audio-Oral Course under web-based environment. Computer-assisted Foreign Language Education, 155, 72-75.

van Lier, L. (2008). Agency in the classroom. In J. P. Lantolf, \& M. E. Poehner (Eds.), Sociocultural Theory and the Teaching of Second Languages (pp. 163-186). London, Oakville: Equinox Publishing Ltd.

Wang, M., \& Wang, D, (2008). Three essential factors to excite initiative of learning English. Journal of Technology College Education, 06, 130-32.

Wei, Wang, \& Yan. (2014). An inquiry to promote student's English learning agency in vocational schools in the perspective of constructivism. Academic Research, 44, 80-81

Zhang, J. (2000). Develop students' agency in English learning. Jiamusi University Journal of Social Science, 02, 
117-118.

Zhao, X. (2014). Developing students' learning agency in English teaching in technical schools. Retrieved from http://www.cnki.net/kcms/detail/11.3173.G4.20140708.1543.001.html

Zhou, P., Jiang, X. \& Hong D. (2012). Factors on undergraduates' low levels of motivation to learn: Theoretical and Empirical Analyses. Renmin University of China Education Journal, 02, 27-36.

\section{Notes}

1. Chinese universities in the"985 program" or "211 program" are specified by the state as key universities for construction to approach the first-class world level. 